\title{
TYPE 2 DIABETES MELLITUS AND ORAL HEALTH PROBLEMS CROSS-SECTIONAL STUDY
}

\author{
Asmaa Abou-Bakr* and Eman Khalil ${ }^{* *}$
}

\begin{abstract}
In Egypt, diabetes mellitus is considered to be a foremost health issue with a major influence on the disease and the rate of death. Diabetes mellitus is a communal disorder having affiliated oral disorders that influence dental care. The purpose of this study was to study the prevalence of oral changes in diabetes type 2 in the Egyptian participants to raise awareness between diabetic patients and dental professionals.

Methods: This was a cross-sectional study that was done on 200 patients who were diagnosed with diabetes mellitus type 2 at Diabetes and Endocrinology Clinic in Kasr Al Ainy, Cairo University Hospital over a period of 2 months from the first of September 2019 to the first of November 2019. Both genders were selected with age ranging from (32-60). A detailed oral examination was performed in accordance with international criteria.

Results: The most prevalent oral changes were caries (58\%), periodontitis (56\%), xerostomia (45\%), taste dysfunction (32.5\%), burning sensation (20\%) and candida (15\%).

Conclusions: This study exhibited that diabetes has harmful influences on oral health status; hence, dentists must be acquainted with the related oral disorders in patients with diabetes as chronic oral complications in these patients could worsen their glucose level and their prognosis. The dentists could have a helpful role in spotting the undiagnosed diabetic patients from the associated oral manifestations.
\end{abstract}

KEYWORDS: Diabetes type 2, changes, caries, periodontitis.

\section{INTRODUCTION}

Diabetes mellitus (DM) is a vital public health concern for the past decades and a standard chronic metabolic malady worldwide ${ }^{(1)}$. DM could be a syndrome of abnormal carbohydrates, fat and protein breakdown that leads to short and future complications because of the shortage of hypoglycemic agent either absolute or relative. The main types of diabetes are: type 1 , indicating an absolute deficiency of insulin; type 2 , due to

* Demonstrator at Department of Oral Medicine and Periodontology, Faculty of Dentistry, British University, Cairo, Egypt. Master candidate at Department of Oral Medicine, Faculty of Dentistry, Ain Shams University, Cairo, Egypt.

** Assistant Professor of Oral Medicine and Periodontology Department, Faculty of Dentistry, British University, Cairo, Egypt. 
resistance of insulin and a secretory fault of the insulin; and physiological state, a condition befell in pregnant females due to abnormal glucose tolerance ${ }^{(2)}$.

Any age can be tormented by DM, however adults are more prone to it. It was stated that this polygenic disease is taking into account to be pandemic by The World Health Organization $(\mathrm{WHO})^{(3)}$. Over the past few decades the frequency of polygenic disease has intensely hyperbolic and it is predictable to triple within the next decade. The microvascular and macrovascular complications of the polygenic disease could be a leading reason of death ${ }^{(4,5)}$. Consequently, diagnosing and managing patients with polygenic disease could be a major role that may be done by the dental team. Additionally, as morbidity and mortality is for the reason that of poorly controlled DM, the diabetic patients ought to consult their dentists regarding aldohexose regulation improvement, oral and nutritionary health maintaining and habitually aldohexose monitoring tests every day ${ }^{(\boldsymbol{(})}$.

Egypt was listed among the world's prime ten countries within the variety of patients with DM by the International Diabetes Federation (IDF) in 2013. The Middle East and North Africa (MENA) region has variety of patients that hyperbolic by ninety six percent from year 2013 to 2035 or from thirty four millions to sixty seven millions. The prevalence of DM in Egypt is around fifteen and half percent among adults between twenty and seventy nine years, with a yearly death of 86,478 related to $\mathrm{DM}^{(7)}$.

\section{MATERIALS AND METHODS}

This was a cross sectional study at Diabetes an Endocrinology Clinic in Kasr Al Ainy, Cairo University Hospitals over a period of 2 months since the first of September 2019 to the first of November 2019 with a convenience sampling performed for
200 patients to detect the prevalence of oral diseases among type 2 diabetes patients and this was based on data from previous study by de Menezes Sousa ${ }^{(8)}$.

Inclusion criteria included Egyptian patients from both genders from age ranging from 32 to 60 years having DM type 2 according to American Diabetes Association, $2019{ }^{(9)}$. Patients who had any other systemic diseases that could affect the prevalence of oral lesions or could have an impact on the oral cavity like hepatitis $\mathrm{C}$, autoimmune conditions, malignancy and patients with a history of receiving chemotherapy or radiotherapy were excluded.

All participants came after overnight fasting on the day of examination. In a calm room (the room of the health visitor), a full history was taken from all the participants including: sociodemographic data, symptoms or signs related to diabetes or impaired glucose tolerance, family history and general medical examination. Demographic data were recorded in the form of age, sex and address and the medical records were assessed for metabolic condition and duration of diabetes. All the participants were asked about their feeling of burning sensation, taste dysfunction or dry mouth; then a comprehensive oral examination was performed using two plain mouth mirrors in order to view lesions, sharp explorer to reveal carious lesions and Williams graduated probe to investigate the periodontal condition more truthfully.

\section{Statistical analysis}

Information was fed to the computer system and analyzed using IBM SPSS software package version twenty. (Armonk, NY: IBM Corp) Qualitative information was designated in numbers and percent. Quantitative information was designated using range (minimum and maximum), mean, standard deviation and median. 


\section{RESULTS}

As showed in table $(1,2)$ Figure $(1,2)$

TABLE (1): Distribution of the studied cases according to demographic data $(n=200)$

\begin{tabular}{l|c}
\hline & No. $(\%)$ \\
\hline Age & \\
$\quad$ Mean \pm SD. & $53.4 \pm 6.7$ \\
$\quad$ Median (Min. - Max.) & $55(32-60)$ \\
\hline Sex & \\
$\quad$ Female & $126(63 \%)$ \\
$\quad$ Male & $74(37 \%)$ \\
\hline
\end{tabular}

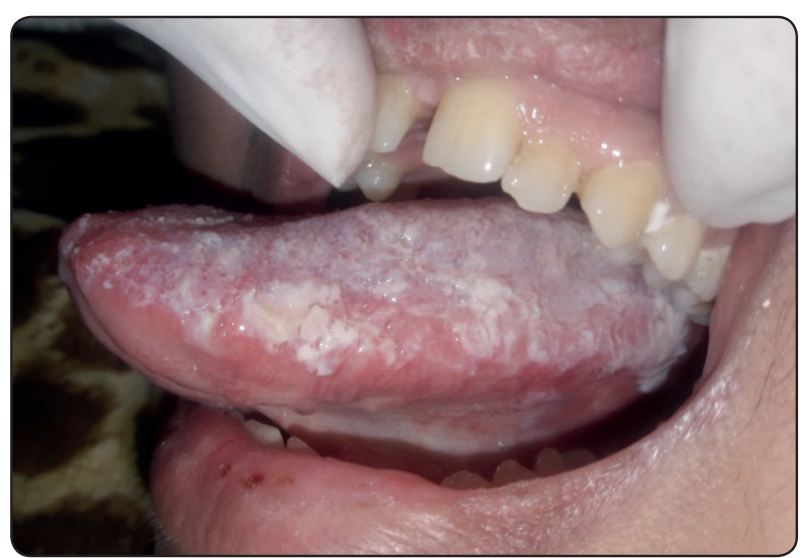

Fig. (2): Showing pseudomembranous candidiasis on the lateral sides of the tongue.

\section{DISCUSSION}

Diabetes mellitus is one of the causes of death and disability all around the world ${ }^{(\mathbf{1 0})}$. The diabetes mellitus prevalence in 2011 worldwide was around $8 \%$ and is expected to increase by $10 \%$ in 2030 . Low and middle-income countries harbor about $80 \%$ of diabetic patients ${ }^{(11)}$.

In the current study it was found that the female participants were more than males with percentage of $63 \%$ to $37 \%$ respectively and this was in accordance with a previous study reported by Mahmoud et al ${ }^{(12)}$ with $76.4 \%$ females and 23.6 $\%$ males. This could attribute to the risk factors of diabetes type 2 like obesity and physical inactivity. Demographic survey (2008) that carried out in

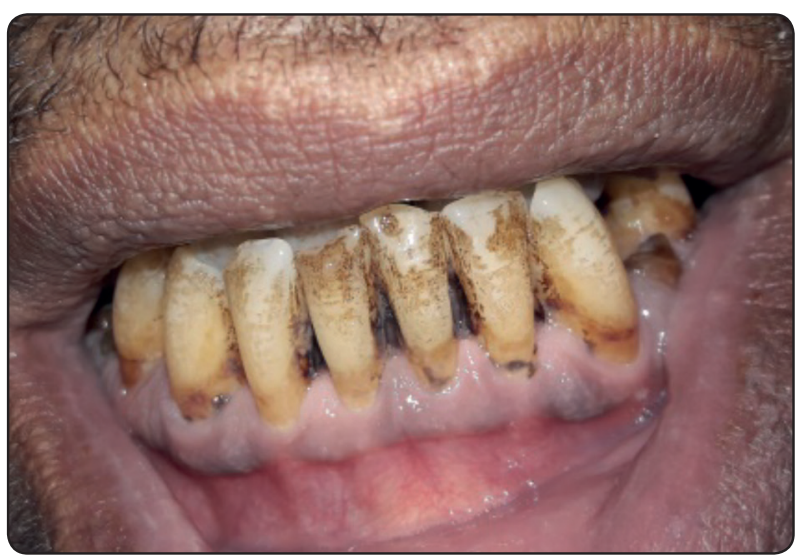

Fig. (1) : Showing periodontal condition.
Egypt reported that nearly $50 \%$ of Egyptian men and $65 \%-80 \%$ of Egyptian women are obese or overweight ${ }^{(7)}$. It was found that $50 \%$ of the surveyed individuals have central obesity by The Egyptian National Hypertension Survey Program, which was conducted in Egyptian governorates and included 2313 adults over 25 years of age, therefore, obesity is considered to be associated with the increased risk of diabetes and cardiovascular disease ${ }^{(7)}$.

Caries was the most prevalent oral changes in the present study with percentage $58 \%$ and this 
was in agreement with several other authors ${ }^{(13-21)}$, while some authors have reported low prevalence of dental caries among diabetics ${ }^{(22-24)}$.

Thiscould be explained by themore frequent meals in diabetic patients than normal patients and repeated intakes of even small amount of carbohydrates may be cariogenic when coupled with elevated blood glucose level and hyposalivation ${ }^{(25)}$. Fundamentally, changes in hydrogen ion concentration in the saliva of these groups of patients are predicted ${ }^{(26)}$. This reduction of hydrogen ion concentration can result in an extremely high cariogenic situation, and accordingly cariogenic bacteria like Treponema denticola, Prevotella nigrescens, many species of Streptococci will increase (27). The proliferation of the latter species can result in a fair lower hydrogen ion concentration, and this spiteful sequence persists, moreover, it has an influence on the protective microflora of the oral cavity growing status ${ }^{(26)}$. Once analyzing some specific categories of diabetes, that is determined in diabetes type 2 there is a correlation with a substantially higher incidence of dental caries and crueler decay ${ }^{(30)}$.

Periodontitis was found in 112 patients out of 200 with prevalence $56 \%$ and this was in accordance with previous studies (28-31). Diabetes type two and periodontal disease appeared to be allied intensely, nevertheless, to take issue geographically, related to factors like genes, educational and ethnic variances ${ }^{(35)}$. There could be a causative bilateral relationship, as when the severity of one pathology is increased (diabetes or periodontitis) can adversely affect the severity of the other. On the opposite hand, the advance of glycemic management in diabetes type 2 is estimated once their periodontal disease is controlled ${ }^{(32)}$. Numerous mechanisms are planned to clarify the inflated vulnerability to periodontitis, as well as changes in the response of the host, subgingival microorganisms, metabolism of collagen, vascularity, sulcular fluid of the gingiva and heredity conditions.
Many pathophysiological mechanisms (impaired function of neutrophil, reduced phagocytosis and leukotaxis) even have been involved within the inflated loss of alveolar bone in diabetic patients ${ }^{(33,34)}$.

Burning sensation was reported in 40 out of 200 of our patients with prevalence $20 \%$ and this was in accordance with other previous studies $(\mathbf{1 2 , 3 5 , 3 6 , 3 7 )}$ with prevalence $(18.8 \%, 17.8 \%, 17.2 \%$ and $10 \%$ respectively). But, the results were conflicting with one study reported in Kingdom of Saudi Arabia who reported a percentage $(39 \%){ }^{(38)}$. This conflict in the prevalence of burning sensation can be attributed to the variability in symptomatology, lack of precise diagnostic criteria, and the different population ${ }^{(39)}$.

The precise explanation for burning mouth is unidentified; however it may be due to many reasons like xerostomia, menopause, candidiasis, diabetes, therapy of cancer, psychological issues and reflux of acid. BMS is categorized into 2 types: 1ry idiopathic, and 2ry due to systemic procedure; 2ry type of BMS has been rumored to occur with diabetes. It might unfavorably have an effect on the flexibility to keep up healthy oral status in diabetic patients. The other explanation of BMS in patients with diabetes is diabetic neuropathy. The nerve injury in diabetic neuropathy has been rumored to indicate a rise within the Langerhans cells that are related with immune disruption. ${ }^{(39,40)}$. Thus, any patients who have BMS symptoms should be critically screened for diabetes.

Xerostomia was found in 90 patients out of 200 with prevalence $45 \%$ and this was in agreement with previous studies with prevalence of $(51 \%$, $47.4 \%, 34 \%$ and $43.8 \%$ respectively) ${ }^{(41-44)}$. Diabetic patients have complained of having dry mouth, or xerostomia, and have suffered from dysfunction in their salivary glands ${ }^{(45,46)}$. The reason is unknown, but it could be due to polyuria, autonomic neuropathies, and microvascular changes and variations in the salivary glands basement membranes ${ }^{(47,48)}$. 
Taste dysfunction was reported in 65 out of 200 patients with prevalence of $32.5 \%$ which was in consistent with previous studies with prevalence of $\left(40.4 \%, 33 \%\right.$ and $40 \%$ respectively) ${ }^{(12,38,48)}$. Alteration in the sense of taste in diabetic patients could attributed to the neuropathic mechanism in the nerves that are responsible for taste. Altered taste sensation had the strongest association with length of diabetes and diabetic neuropathy ${ }^{(49)}$, likewise because dehydration of mucosa, reduced production of gustin, lack of zinc and coating of the tongue ${ }^{(41)}$.

Candida was found in thirty out of two hundred patients in our study with prevalence of $15 \%$ and it was in accordance with other studies which reported prevalence $(15 \%, 24 \%$ and $21 \%$ respectively) ${ }^{(43,37,50)}$.

The prevalence of candidiasis in diabetic patients has been documented several years $\mathrm{ago}^{(51)}$. Candidiasis is widely predominant among diabetic patients particularly smokers, dentures wearers, those with poor glycemic control and the diabetic patients on steroids and broad spectrum antibiotics ${ }^{(52)}$. Furthermore, diabetic patients had salivary dysfunction that could be due to the greater prevalence of candida in diabetic patients. It is obvious from previous scholarships that locally and systematically disposing influences that could increase the rate of fungal infections risk in diabetic patients ${ }^{(53)}$.

\section{CONCLUSIONS}

The consequences of poor oral health could also be additionally severe in diabetes patients attributable to advanced age and impaired glucose levels which will increase the chance for general consequences of oral and dental pathologic conditions. Dentist should recruit the diabetic patients to keep their oral cavity in a good and healthy status and counseling them towards a proper diet. Meeting these patients' oral health needs is of predominate importance, since this is able to improve the oral health-related quality of life, and this might be achieved by putting in associate integrated oral health intervention involving general health care practitioners and dentists.

\section{RECOMMENDATIONS}

1. Appropriate and effective oro-dental health care programs oriented to the diabetic patients and tested in clinical trials.

2. A national oral health promotion campaign should be carried out targeting diabetic patients to raise their awareness of the need for dental visits (even if they are edentulous).

3. An adequate number of trained hygienist and dental assistants are also of importance in the outpatient clinics to participate in the treatment plans.

4. The present study is recommended to be applied in other governorates because it may help in the awareness with the extent of presence of different oral lesions throughout republic.

\section{REFERENCES}

1. Abegunde DO, Mathers CD, Taghreed A, Ortegon M, Strong K.: The burden and costs of chronic diseases in low-income and middle-income countries. Lancet., 370:1929-38, 2007.

2. Jonathan AS, D.M.D.: Diabetes and oral health An overview. JADA., Vol. 134, Oct, 2003.

3. World Health Organization. Global Prevalence of Diabetes: Estimates for the Year 2000 and Projections for 2030. Geneva: World Health Organization., 2009.

4. Moore PA, Zgibor JC, Dasanayake AP.: Diabetes: A growing epidemic of all ages. J Am Dent Assoc., 134:11-15, 2003.

5. Shelesh J, Swarnlata S.: Type 2 diabetes mellitus - Its global prevalence and therapeutic strategies. Diabetes Metab Syndr., 4:48-56, 2010.

6. Lalla RV, D'Ambrosio JA.: Dental management considerations for The patient with diabetes mellitus. JADA., 132:1425-32, 2001. 
7. Hegazi R,El-Gamal M, Abdel-Hady N, Hamdy O.: Epidemiology of and Risk Factors for Type 2 Diabetes in Egypt. Annals of Global Health., Vol 81, Issue 6, November-December, Pages 814-820, 2015.

8. De Menezes Sousa MG, de Lisboa Lopes Costa A, Roncalli AG.: Clinical study of the oral manifestations and related factors in type 2 diabetics patients. Braz J Otorhinolaryngol., 77(2):145-52, 2011.

9. American Diabetes Association.: 'Standards of Medical Care in Diabetes', Diabetes care, 42(1), 2019.

10. Lozano R, Naghavi M, Foreman K, Lim S, Shibuya K, Aboyans V, et al:: Global and regional mortality from 235 causes of death for 20 age groups in 1990 and 2010: a systematic analysis for the Global Burden of Disease Study 2010. Lancet., 380:2095-2128, 2012.

11. International Diabetes Federation (IDF).: Country estimates table 2011. IDF diabetes atlas 2012, 6th ed.; 2012. [Accessed 7 June 2014].

12. Mahmoud A, Abdel Moneim W, Fakhr M, El -Sawy SS.: Prevalence of Burning Mouth Syndrome in A sample of Egyptian Patients with Diabetic Neuropathy: A Cross Sectional Hospital-Based Study. Advanced Dental Journal., Vol 2 I Issue 2l Pages 34- 42, 2020.

13. Pearce EI, Dong YM, Yue L, Gao XJ, Purdie GL, Wang JD.: Plaque minerals in the prediction of caries activity. Community Dent Oral Epidemiol., 30:61-9, 2002.

14. Reddy CVK, Maurya M.: A comparative study to assess the oral health status and treatment needs of diabetic and non diabetic population attending some of the hospitals in Mysore city. J Indian Assoc Public Health Dent., 12:1-14, 2008.

15. Kanjirath PP, Inglehart MR, Habil P.: Diabetes and oral health: The importance of oral health related behavior. The Journal of Dental Hygiene., 85:264-72, 2011.

16. Sadia I, Farhat K, Saad A, Muhammad M, Ayyaz AK.: Dental caries and diabetes. Pak Oral Dent J., 31:58-61, 2011.

17. Kampoo K, Teanpaisan R, Ledder RG, McBain AJ.: Oral bacterial communities in individuals with type 2 diabetes who live in southern Thailand. Appl Environ Microbiol., 80:662-71, 2014.

18. Moin M, Malik A.: Frequency of dental caries and level of risk among type II diabetics. Dentistry., 5:334-8, 2015.
19. Cao X, Wang D, Zhou J, Yuan H, Chen Z.: Relationship between dental caries and metabolic syndrome among 13998 middle-aged urban Chinese. J Diabetes., 2016.

20. Seethalakshmi C, Reddy RC, Asifa N, Prabhu S.: Correlation of Salivary $\mathrm{pH}$, Incidence of Dental Caries and Periodontal Status in Diabetes Mellitus Patients: A Crosssectional Study. J Clin Diagn Res., 10:12-4, 2016.

21. Singh I, Singh P, Singh A, Singh T, Kaur R.: Diabetes an inducing factor for dental caries: A case control analysis in Jammu. J Int Soc Prev Community Dent., 6:125-9, 2016.

22. Puranik MA, Hiremath SS.: Oral health status and treatment needs among adult diabetic and non diabetic patients in Banglore city- A comparative study. J Indian Assoc Public Health Dent., 4:31-7, 2006.

23. Gupta VK, Malhotra S, Sharma V, Hiremath SS.: The Influence of Insulin Dependent Diabetes Mellitus on Dental Caries and Salivary Flow. Int J Chronic Dis., 790898, 2014.

24. Bissong M, Azodo CC, Agbor MA, Nkuo-Akenji T, Fon PN.: Oral health status of diabetes mellitus patients in Southwest Cameroon. Odontostomatol Trop., 38:49-57, 2015.

25. Novotna M, Podzimek S, Broukal Z, Lencova E, Duskova J.: Periodontal Diseases and Dental Caries in Children with Type 1 Diabetes Mellitus. Mediators Inflamm., 379626, 2015.

26. Seethalakshmi C, Reddy R, Asifa N, Prabhu S.: Correlation of Salivary pH, Incidence of Dental Caries and Periodontal Status in Diabetes Mellitus Patients: A Cross-sectional Study. J Clin Diagn Res., 10(3): 4-12, 2016.

27. Satoru Y, Masato U, Shunichi M.: Association between numbers of decayed teeth and HbA1c in Japanese patients with type 2 diabetes mellitus. Ups J Med Sci., 122(2): 108113.20, 2017.

28. Ship JA. Diabetes and oral health: an overview.: J Am Dent Assoc., 134 Spec No: 4S-10S, 2003.

29. Daniel R, Gokulanathan S, Shanmugasundaram N, Lakshmigandhan M, Kavin T.: Diabetes and periodontal disease. J Pharm Bioallied Sci., 4: S280-S282, 2012.

30. Indurkar MS, Maurya AS, Indurkar S.: Oral Manifestations of Diabetes. Clin Diabetes., 34: 54-57, 2016.

31. Khan T.: Oral manifestations and complications of diabetes mellitus: A review. Int J Med Health Res., 4: 50-52, 2018. 
32. Susanto H, Nesse W, Dijkstra P, Agustina D, Vissink A, et al.: Periodontitis prevalence and severity in Indonesians with type 2 diabetes. J Periodontol; 82(4): 550-557.22, 2011.

33. Oliver RC, Tervonen T.: Diabetes: a risk factor for periodontitis in adults? J Periodontol., 65(supplement 5): 530-8, 1994.

34. Taylor GW, Burt BA, Becker MP, Genco RJ, Shlossman M.: Glycemic control and alveolar bone loss progression in type 2 diabetes.Ann Periodontol., 3(1):30-9, 1998.

35. Collin, H. L. et al.:'Oral symptoms and signs in elderly patients with type 2 diabetes mellitus. A focus on diabetic neuropathy.', Oral surgery, oral medicine, oral pathology, oral radiology, and endodontics., 90(3), pp.299-305, 2000.

36. Arap, A. et al.: 'Trigeminal pain and quantitative sensory testing in painful peripheral diabetic neuropathy', archives of oral biology., 55, pp. 486-493, 2010.

37. Bajaj, S. et al.: 'Oral manifestations in type-2 diabetes and related complications', Indian Journal of Endocrinology and Metabolism., 16(5), p. 777, 2012.

38. Ouda, S. and Al-attas, S. A.: 'Hyperglycemia and Oral mucOsal lesiOns amOng diabetic patients in JeddaH city', egyptian dental journal., 55 No. 2, pp. 1-10, 2009.

39. Moore, P. A., Guggenheimer, J. and Orchard, T.: 'Burning mouth syndrome and peripheral neuropathy in patients with type 1 diabetes mellitus', Journal of Diabetes and its Complications., 21(6), pp. 397-402, 2007.

40. Tavakoli M, Boulton AJ, Efron N, Malik RA.: Increased Langerhans cell density and corneal nerve damage in diabetic patients: Role of immune mechanisms in human diabetic neuropathy. Cont Lens Anterior Eye., 2010.

41. Al-Maskari AY, Al-Maskari MY, Al-Sudairy S.: Oral Manifestations and Complications of Diabetes Mellitus: A review. Sultan Qaboos Univ Med J., 11: 179-186, 2011.

42. de Souza Bastos, A. et al.: 'Diabetes mellitus and oral mucosa alterations: Prevalence and risk factors', Diabetes Research and Clinical Practice., 92(1), pp, 2011.

43. Cicmil S, Mladenović I, Krunić J, Ivanović D, Stojanović N.: Oral Alterations in Diabetes Mellitus. Balk J Dent Med., 22: 7-14, 2018.
44. Guinan, J. C. et al.: 'Analysis of the Relationship between Oral Diseases and Glycemic Control of Diabetes in the West African Context: Survey at the Centre AntiDiab\&\#233;tique d'Abidjan (CADA), C\&\#244;te d'Ivoire', Open Journal of Epidemiology., 08(04), pp. 213-225, 2018.

45. Field EA, Longman LP, Bucknall R, Kaye SB, Higham SM, Edgar WM.: The establishment of a xerostomia clinic: a prospective study. Br J Oral Maxillofac Surg., 35(2):96103, 1997.

46. Chavez EM, Borrell LN, Taylor GW, Ship JA.: A longitudinal analysis of salivary flow in control subjects and older adults with type 2 diabetes. Oral Surg Oral Med Oral Pathol Oral Radiol Endod., 91:166-73, 2001.

47. Cicmil A, Govedarica O, Lečić J, Mališ S, Cicmil S, Čakić S.: Oral Symptoms and Mucosal Lesions in Patients with Diabetes Mellitus Type 2. Balk J Dent Med., 21: 50-54, 2017.

48. Mauri-Obradors E, Estrugo-Devesa A, Jané-Salas E, Viñas M, López-López J.: Oral manifestations of Diabetes Mellitus. A systematic review. Med Oral Patol Oral Cir Bucal., 22: e586-e594, 2017.

49. Latha GS, DM, C. and Puranik, N.: 'Altered taste threshold in chronic Type 2 diabetes mellitus', National Journal of Physiology, Pharmacy and Pharmacology., 8(4), pp. 569$574,2017$.

50. Bissong, M. E. A. et al.: 'Oral health Status of diabetic patients in South West Oral health status of diabetes mellitus patients in Southwest Cameroon', Tropical dental journal., 38(150), pp. 49-57, 2015.

51. Lamey PJ, Darwaza A, Fisher BM, Samaranayake LP, MacFarlane TW, Frier BM.: Secretor status, candidal carriage and candidal infection in patients with diabetes mellitus. J Oral Pathol., 17:354-7, 1988.

52. Willis AM, Coulter WA, Fulton CR, Hayes RJ, Bell PM, Lamey PJ.: Oral candidal carriage and infection in insulin treated diabetic patients. Diabet Med., 16:675-9, 1999.

53. Soysa NS, Samaranayake LP, Ellepola NB.: Diabetes mellitus as a contributory factor in oral candidosis. Diabet Med., 23:455-9, 2006. 